\title{
Estabelecimento de sistema bacteriano de expressão de peptídeos derivados da enzima vegetal RuBisCO
}

\section{The establishment of a bacterial expression system for peptides derived from the vegetable enzyme RuBisCO}

\author{
Jessica Audrey Feijó Corrêa ${ }^{1 *}$ (1), Svetlana Yurgel², Chibuike Udenigwe², \\ Fernando Bittencourt Luciano ${ }^{1}$
}

${ }^{1}$ Pontifícia Universidade Católica do Paraná (PUC-PR), Escola de Ciências da Vida, Programa de Pós-graduação em Ciência Animal, Curitiba/PR - Brasil

${ }^{2}$ Dalhousie University, Department of Plant, Food and Environmental Sciences, Truro/NS - Canadá

${ }^{3}$ University of Ottawa, Department of Chemistry and Biomolecular Sciences, Ottawa/ON - Canadá

*Corresponding Author: Jessica Audrey Feijó Corrêa, Pontifícia Universidade Católica do Paraná (PUC-PR), Escola de Ciências da Vida, Programa de Pós-graduação em Ciência Animal, Rua Imaculada Conceição, 1155, CEP: 80215-901, Curitiba/PR - Brasil, e-mail: jessica.feijo@pucpr.edu.br

Cite as: Corrêa, J. A. F., Yurgel, S., Udenigwe, C., \& Luciano, F. B. (2019). The establishment of a bacterial expression system for peptides derived from the vegetable enzyme RuBisCO. Brazilian Journal of Food Technology, 22, e2018180. https://doi.org/10.1590/1981-6723.18018

\begin{abstract}
Resumo
O objetivo do presente estudo foi estabelecer um sistema bacteriano de expressão de peptídeos derivados da proteólise simulada in silico da enzima ribulose-1,5-bisfosfato carboxilase oxigenase (RuBisCO), proveniente de soja, visando viabilizar um método sustentável de produção dessas moléculas para futura aplicação industrial. Inicialmente, foi conferida à cepa Escherichia coli S17-1 cálcio-competência para propagação do plasmídeo de expressão pET-30a(+) contendo o inserto codificante da sequência peptídica GSIKAFKEATKVDKKVVVLWTALVPR. Após extração de DNA plasmidial, o material foi transformado em células de alto rendimento $E$. coli Rosetta $^{\mathrm{TM}}(\mathrm{DE} 3)$ pLysS. As células Rosetta portando o plasmídeo de expressão foram induzidas e a produção dos peptídeos foi verificada por meio de eletroforese em gel vertical, confirmando o estabelecimento de um sistema de expressão viável para peptídeos heterólogos. Assim, a produção em maior escala de peptídeos derivados de RuBisCO - associando-se futuramente etapas de purificação e ativação - torna-se possível. Além disso, o método aqui estabelecido pode também ser aplicado utilizando diferentes sequências peptídicas com atividade antimicrobiana.
\end{abstract}

Palavras-chave: Alternativas antimicrobianas; Transformação; Peptídeos bioativos; Expressão heteróloga; Vetor plasmidial; Clonagem.

\begin{abstract}
The objective of this research was to establish a bacterial expression system for peptides derived from the in silico simulated proteolysis of the enzyme ribulose-1,5-bisphosphate carboxylase/oxygenase obtained from soybeans, aiming to make a sustainable method for the production of these molecules feasible for future industrial application.
\end{abstract}


Firstly, the Escherichia coli S17-1 strain was made calcium-competent for the propagation of the expression plasmid pET-30a $(+)$, carrying the coding insert for the peptide sequence GSIKAFKEATKVDKVVVLWTALVPR. After plasmid DNA extraction, the material collected was transformed into high-efficient $E$. coli Rosetta ${ }^{\mathrm{TM}}$ (DE3)pLysS cells. Rosetta cells carrying the expression plasmid were then induced and peptide production verified through vertical gel electrophoresis, confirming the establishment of a viable expression system for heterologous peptides. Thus, the larger scale production of RuBisCO-derived peptides - along with future purification and activation steps - became possible. In addition, the method set forth herein may also be applied to different peptidic sequences with antimicrobial activity.

Keywords: Antimicrobial alternatives; Transformation; Bioactive peptides; Heterologous expression; Plasmid vector; Cloning.

\section{Introdução}

A busca por alternativas naturais para substâncias antimicrobianas tem aumentado consideravelmente visto a crescente preocupação com o uso indiscriminado de produtos sintéticos. Além de uma crescente parcela da sociedade manifestar objeção ao consumo de fórmulas contendo essas substâncias (Nielsen Europe, 2015), muitos micro-organismos têm se tornado resistentes a compostos tradicionalmente utilizados (Hyldgaard et al., 2012), sendo que essa situação é considerada um dos maiores desafios na saúde pública e na indústria mundial, nos dias de hoje (Luepke et al., 2017).

A indústria de alimentos utiliza substâncias antimicrobianas para evitar contaminação dos produtos e prolongar sua vida de prateleira. Diferentes alternativas naturais para aplicação em alimentos vêm sendo estudadas e aplicadas, tais como óleos essenciais (Calo et al., 2015), componentes de óleos essenciais (Lopes et al., 2018; Nazareth et al., 2018), extratos vegetais (Abdollahzadeh et al., 2014), ácidos fenólicos (Meira et al., 2017), bacteriocinas (Johnson et al., 2018), bem como enzimas e peptídeos obtidos de fontes alimentares, tais como a lisozima, obtida do ovo, e a lactoferrina, obtida do leite (Pellegrini, 2003; Udenigwe \& Aluko, 2012; Corrêa et al., 2018).

Os peptídeos antimicrobianos (PAMs) estão amplamente distribuídos na natureza e apresentam relativa estabilidade quando comparados a outras moléculas antimicrobianas, tais como os óleos essenciais voláteis (Calo et al., 2015; Rigotti et al., 2017). Quando comparados entre si, os PAMs de cadeia curta se destacam por apresentarem maior estabilidade (Udenigwe \& Aluko, 2012). A atividade antimicrobiana de peptídeos de cadeia curta pode ser pesquisada in silico utilizando ferramentas de bioinformática, que avaliam a estrutura primária de uma proteína-origem (Udenigwe, 2014). Mais especificamente, são verificados os potenciais de bioatividade de peptídeos crípticos contidos na sequência da proteína, indicando a possibilidade de estes passarem a apresentar propriedades diferenciadas após liberados. Essa avaliação pode ser baseada em prováveis reações proteolíticas e/ou interações entre aminoácidos da sequência que o programa simula, ou em comparações com banco de dados, variando de acordo com o software utilizado (Udenigwe \& Aluko, 2012; Udenigwe, 2014).

Udenigwe et al. (2013), utilizando as ferramentas de bioinformática ExPASy (Gasteiger et al., 2003), BIOPEP (Minkiewicz et al., 2008) e Bioware (Mooney et al., 2012), avaliaram as subunidades da ribulose-1,5bisfosfato carboxilase oxigenase (RuBisCO) de cereais, visando verificar in silico a bioatividade de peptídeos obtidos por digestão proteolítica simulada. Os resultados foram altamente promissores, indicando alta bioatividade ( $>90 \%$ ) dos peptídeos derivados das subunidades da enzima, especificamente relacionada ao forte caráter anfipático desses fragmentos. Essa característica confere função antimicrobiana a inúmeros peptídeos já avaliados in vitro (Oren \& Shai, 1998), uma vez que permite à molécula interagir com a membrana da célula alvo, causando desestabilização, extravasamento e conseguinte morte (Pellegrini, 2003). 
O presente estudo objetivou estabelecer um sistema bacteriano para expressão de peptídeos com potencial antimicrobiano - verificado previamente in vitro - derivados da RuBisCO de soja (Glycine max L.), visando à futura produção voltada à aplicação industrial.

\section{Material e métodos}

\subsection{Reagentes, plasmídeos e micro-organismos}

O plasmídeo pET-30a(+) (Figura 1) para expressão foi adquirido da GenScript (2018, Piscataway, NJ) já contendo 12 repetições em tandem da sequência codificadora do peptídeo críptico da RuBisCO GSIKAFKEATKVDKVVVLWTALVPR (Figura 2, inserto genericamente denominado Soy_IPS_12) clonadas em BamHI / EcoRI - seguidas da etiqueta de poli-histidina (His-tag).

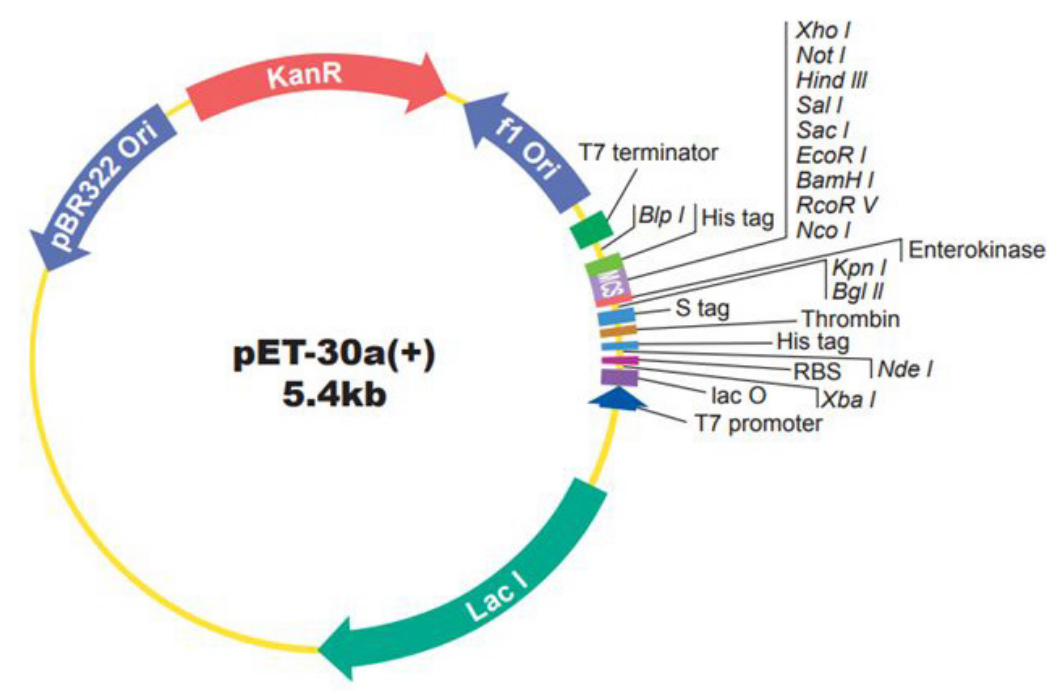

Figura 1. Representação do plasmídeo pET-30a(+). Indicação dos sítios de clonagem e regiões reguladoras (GenScript, 2018).

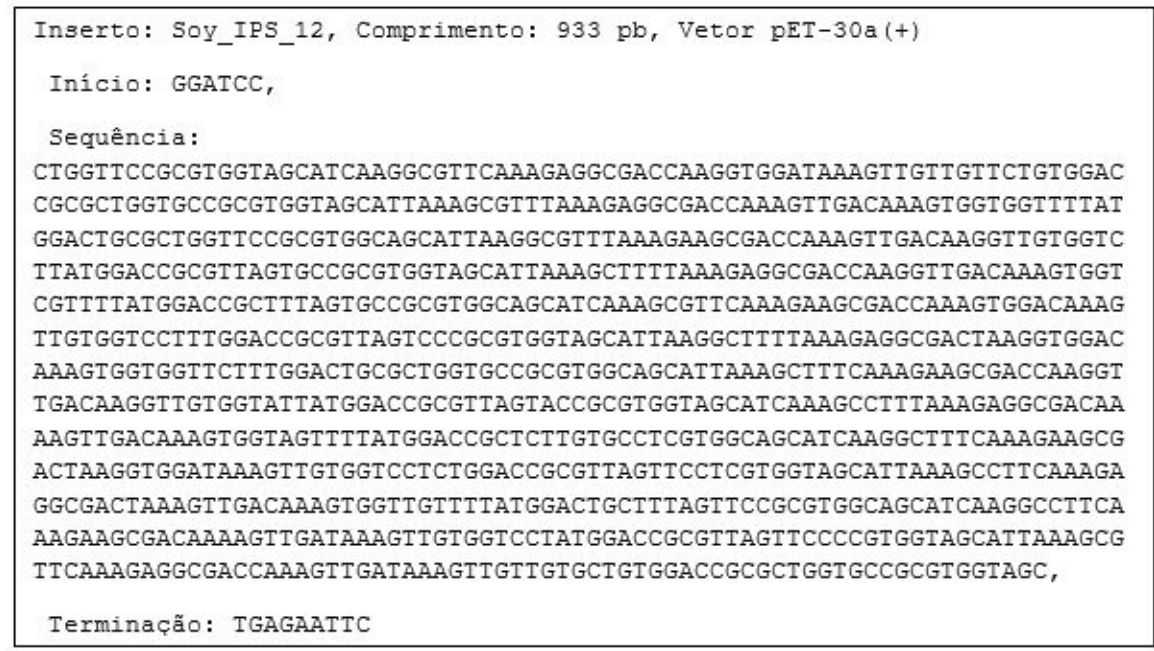

Figura 2. Sequência nucleotídica inserida no plasmídeo. Cada letra representa um nucleotídeo (A - adenina; $\mathrm{T}$ - timina; G - guanina; C - citosina).

A cepa utilizada para propagação dos plasmídeos Escherichia coli S17-1, assim como a cepa Sinorhizobium meliloti 1021, transformada previamente com plasmídeo pET-30a(+) sem inserto 
(denominado genericamente aqui de plasmídeo teste), foram cedidas pelo Molecular Microbiology Laboratory da Dalhousie University Agricultural Campus (Truro, Canadá). A cepa escolhida para estabelecer o sistema de expressão foi E. coli $\operatorname{Rosetta}^{\mathrm{TM}}(\mathrm{DE} 3) \mathrm{pLysS}$ (Rosetta), fornecida pela Novagen (2004, EMD Biosciences, Darmstadt, Alemanha).

Quando não especificados, os reagentes utilizados nos procedimentos foram de grau analítico e fornecidos pela Sigma-Aldrich Co. (St. Louis, MO). O meio utilizado para manipulação e manutenção das culturas bacterianas foi o meio complexo Lysogeny Broth Lennox (LB-L), composto por triptona $10 \mathrm{~g} \mathrm{~L}^{-1}$ (BD Biosciences, Franklin Lakes, NJ), extrato de levedura $5 \mathrm{~g} \mathrm{~L}^{-1}$ (BD Biosciences), cloreto de sódio $5 \mathrm{~g} \mathrm{~L}^{-1}$ (Fisher BioReagents, Fair Lawn, NJ) e, quando sólido, com adição de ágar $15 \mathrm{~g} \mathrm{~L}^{-1}$ (Fisher Chemical, Fair Lawn, NJ). O antibiótico para seleção de colônias transformantes com plasmídeos pET-30a(+) foi canamicina $40 \mu \mathrm{g} \mathrm{mL}^{-1}$ (Fisher Scientific, Fair Lawn, NJ).

\subsection{Atribuição de competência a E. coli S17-1}

Inicialmente, o plasmídeo contendo o inserto foi propagado, visto que é fornecido em pequenas quantidades. Para isso, optou-se por atribuir competência química para transformação molecular com uso de cloreto de cálcio a células Escherichia coli S17-1. Essa cepa apresenta boa eficiência na propagação de plasmídeos (Kristensen et al., 1995). As células foram submetidas ao procedimento de competência química com cloreto de cálcio de acordo com a metodologia adaptada de Krantz Laboratory (2016; Department of Molecular \& Cell Biology, University of California, Berkeley, CA). As células S17-1 foram incubadas por $18 \mathrm{~h}$ a $28{ }^{\circ} \mathrm{C}$ (Heratherm Incubator IGS180, Thermo Scientific, Waltham, MA) em placas de meio LB-L. Na sequência, uma colônia isolada foi inoculada em $10 \mathrm{~mL}$ de LB-L líquido e incubada a $28^{\circ} \mathrm{C}$ e $110 \mathrm{rpm}$ (MaxQ HP 480 Digital Shaker, VWR, Radnor, PA). A cultura total foi então inoculada em 1 L de LB-L e incubada sob as mesmas condições anteriores, sendo a densidade ótica a $600 \mathrm{~nm}\left(\mathrm{DO}_{600}\right)$ verificada periodicamente até atingir 0,35 a 0,4 , quando foi transferida para banho de gelo e resfriada por aproximadamente $30 \mathrm{~min}$. A cultura foi centrifugada a $3000 \times \mathrm{g}$ por $15 \mathrm{~min}$ a $4{ }^{\circ} \mathrm{C}$ (Sorvall ST $16 \mathrm{R}$, Thermo Scientific), sendo então o sobrenadante descartado e o precipitado ressuspendido com cerca de $100 \mathrm{~mL}$ de $\mathrm{MgCl}_{2} 100 \mathrm{mM}$. Centrifugou-se novamente a suspensão de células a $2000 \times \mathrm{g}$ por $15 \mathrm{~min}$ a $4{ }^{\circ} \mathrm{C}$ e descartou-se o sobrenadante. O precipitado foi novamente ressuspendido com $200 \mathrm{~mL}$ de $\mathrm{CaCl}_{2} 100 \mathrm{mM}$, deixando-se reagir em banho de gelo por $25 \mathrm{~min}$. Após esse período, as células foram colhidas $\left(2000 \times \mathrm{g}, 15 \mathrm{~min}, 4{ }^{\circ} \mathrm{C}\right)$, ressuspendidas em $2 \mathrm{~mL}$ de $\mathrm{CaCl}_{2} 85 \mathrm{mM}$ em glicerol 15\% e aliquotadas em microtubos estéreis no volume de $50 \mu \mathrm{L}$. Os microtubos foram então congelados com nitrogênio líquido e estocados a $-80^{\circ} \mathrm{C}$, até a utilização nos procedimentos de propagação. Todas as soluções e frascos foram mantidos e manipulados em banho de gelo. Um esquema do procedimento realizado pode ser observado na Figura 3.

\subsubsection{Verificação de cálcio-competência adquirida}

A competência adquirida pelas células $E$. coli $\mathrm{S} 17-1$ foi testada a partir da transformação com o plasmídeo teste (pET-30a $(+)$ sem inserto, seleção por canamicina), previamente extraído com kit QIAprep ${ }^{\circledR}$ Spin Miniprep (QIAGEN, Hilden, Alemanha) da cepa S. meliloti portadora. A concentração da solução plasmidial foi determinada previamente utilizando Take3 Micro-Volume Plate (Biotek, Winooski, VT) em leitor de microplacas Hybrid Multi-Mode Synergy H1 ${ }^{\mathrm{TM}}$ (Biotek).

A transformação com o plasmídeo teste foi realizada de acordo com o protocolo da GenScript Inc., em que um microtubo contendo as células S17-1 submetidas ao procedimento de conferência de cálcio-competência foi descongelado em banho de gelo por 25 min e incubado com cerca de $300 \mathrm{ng}$ do plasmídeo. O microtubo foi então submetido a um choque térmico de curta duração $\left(42{ }^{\circ} \mathrm{C}, 120 \mathrm{~s}\right)$ em bloco de aquecimento (VWR Heat Block, VWR), retornado ao banho de gelo por 2 min e acrescido de $800 \mu \mathrm{L}$ de LB-L, sendo então transferido para incubadora tipo shaker $\left(28^{\circ} \mathrm{C}, 110 \mathrm{rpm}\right)$ por $40 \mathrm{~min}$. Na sequência, o conteúdo do tubo foi semeado em placas LB-L suplementadas com canamicina, sendo essas incubadas em estufa $\left(28^{\circ} \mathrm{C}, 48 \mathrm{~h}\right)$. A verificação 
do sucesso do procedimento consistiu na seleção das colônias pelo antibiótico. Além disso, o DNA plasmidial das colônias selecionadas foi também extraído e verificado por eletroforese em gel horizontal, comparando com amostras das extrações anteriores da cultura de $S$. melitoti.

Controles negativos da transformação também foram preparados de acordo com esse protocolo para assegurar que a cepa S17-1 não era originalmente competente e/ou não estava contaminada.

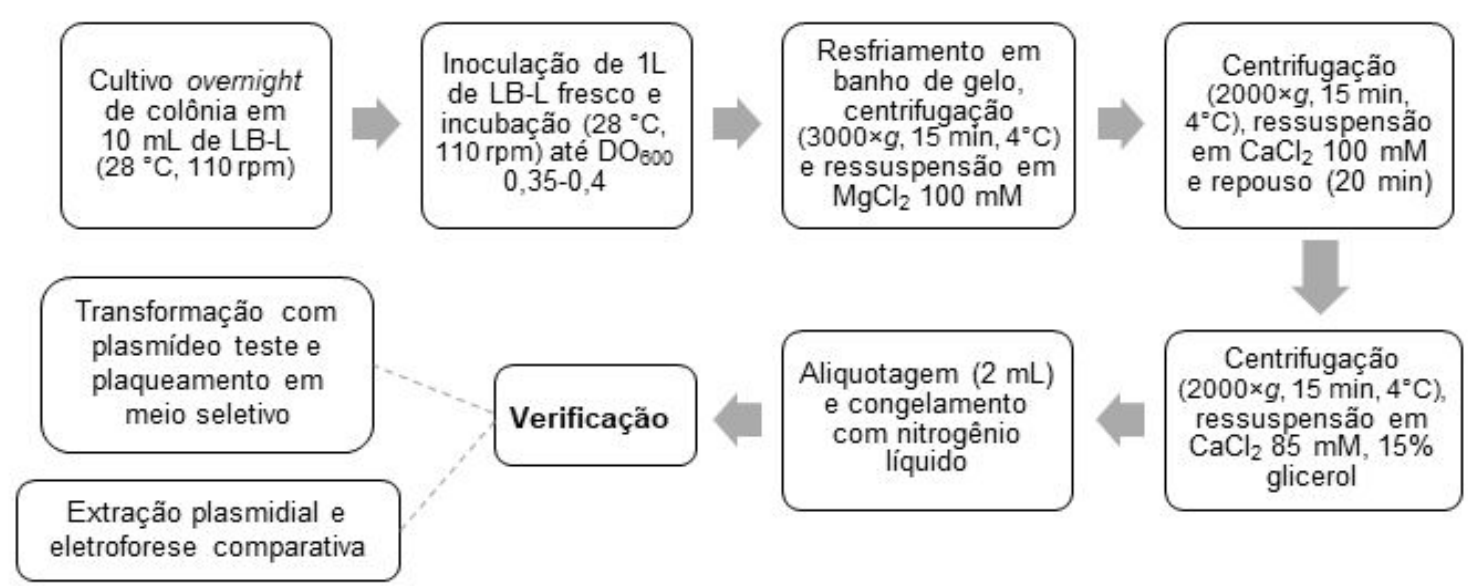

Figura 3. Esquema do procedimento de atribuição de cálcio-competência. As células E. coli $\mathrm{S} 17-1$ foram submetidas ao procedimento após ativação em LB-L (incubação a $28^{\circ} \mathrm{C}$ por $18 \mathrm{~h}$ ).

O detalhamento da etapa de transformação utilizada como verificação neste procedimento é fornecido na Figura 4.

\subsection{Propagação de plasmídeos em S17-1 competente}

Uma vez provada a eficiência na transformação das células S17-1, foi iniciada a propagação do plasmídeo pET-30a $(+)$ contendo o inserto Soy_IPS_12. O protocolo de transformação utilizado foi o mesmo da verificação de competência da S17-1. Após crescimento das colônias selecionadas em meio LB-L contendo antibiótico, foi realizada a extração do DNA plasmidial e o material coletado foi armazenado a $-20{ }^{\circ} \mathrm{C}$ até a utilização.

\subsection{Transformação em E. coli Rosetta ${ }^{\mathrm{TM}}$ (DE3)pLysS}

A partir da propagação e coleta dos plasmídeos pET-30a(+), foi iniciada a transformação em células competentes Rosetta ${ }^{\mathrm{TM}}(\mathrm{DE} 3)$ pLysS, de acordo com o protocolo da GenScript Inc. Além da transformação com os plasmídeos pET-30a(+) propagados, o procedimento foi também executado com o plasmídeo teste.

As colônias transformadas com o plasmídeo pET-30a(+) contendo Soy_IPS_12 e selecionadas por canamicina foram mantidas continuamente em placas com o antibiótico e estocadas a $-80{ }^{\circ} \mathrm{C}$ em glicerol $25 \%$ (Figura 4). 


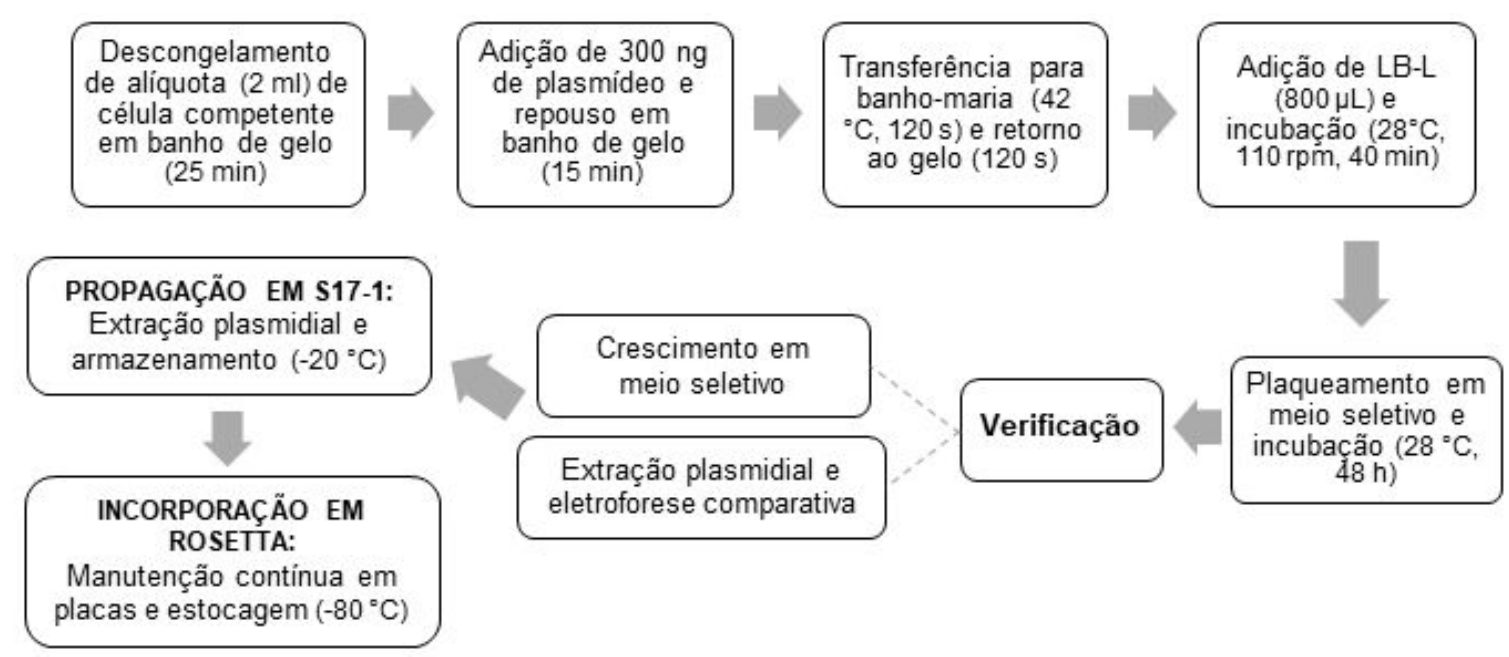

Figura 4. Esquema do procedimento de transformação. As cepas de E. coli S17-1 e RosettaTM(DE3)pLysS foram submetidas ao procedimento visando a propagação e incorporação do plasmídeo, respectivamente.

\subsection{Indução da expressão e verificação}

A verificação do sucesso da transformação dos plasmídeos em células Rosetta consiste, além dos procedimentos de verificação por extração de DNA plasmidial e eletroforese, na indução da expressão dos peptídeos em tandem pelas células (Figura 5). Esse procedimento consiste em estimular quimicamente as células Rosetta transformadas visando à produção do multímero codificado pela sequência inserida utilizando o vetor. Para isso, uma colônia selecionada foi inoculada em 1 L de meio LB-L e incubada sob agitação $\left(28^{\circ} \mathrm{C}, 110 \mathrm{rpm}\right.$ ), sendo realizadas medições periódicas de sua $\mathrm{DO}_{600}$ até atingir 0,5 , quando então foram adicionados $250 \mu \mathrm{L}$ de isopropil $\beta$-D-1-tiogalactopiranosida (IPTG) $400 \mathrm{mM}$. O frasco foi transferido para banho Dubnoff (VWR Shaking Water Bath, VWR) a $4{ }^{\circ} \mathrm{C}$ e $150 \mathrm{rpm}$ por $18 \mathrm{~h}$.

A cultura foi centrifugada $\left(5.000 \times \mathrm{g}, 10 \mathrm{~min}, 4{ }^{\circ} \mathrm{C}\right)$ e o precipitado ressuspendido em $6 \mathrm{~mL}$ de tampão fosfato-salino $1.000 \mathrm{mM}$ (PBS). Alíquotas de $1 \mathrm{~mL}$ foram transferidas para tubos para lise contendo microesferas de vidro de 0,1 mm (Micro-Organism Lysing Mix Nuclease Free, OMNI Inc., Kennesaw, GA) e homogeneizadas por $60 \mathrm{~s}$ no Bead Ruptor 4 Homogenizer (OMNI Inc.). Os tubos foram então centrifugados por $30 \mathrm{~s}$ para sedimentação das partículas (Eppendorf Centrifuge 5424, Eppendorf, Hamburgo, Alemanha). O precipitado foi descartado e o sobrenadante transferido para microtubos para verificação por eletroforese de proteínas utilizando Mini Gel Bolt ${ }^{\mathrm{TM}}$ 4-12\% Bis-Tris (Invitrogen, Carlsbad, CA). Antes da aplicação no gel, as amostras foram preparadas com adição de Bolt ${ }^{\mathrm{TM}}$ LDS Sample Buffer (Life Technologies, Carlsbad, CA) na proporção 4:1 e transferidas para bloco de aquecimento $\left(70^{\circ} \mathrm{C}, 10 \mathrm{~min}\right)$ (VWR Heat Block, VWR). Foram aplicados $20 \mu \mathrm{L}$ por poço e a corrida eletroforética foi realizada em cuba Bolt ${ }^{\mathrm{TM}}$ Mini Gel $(165 \mathrm{~V}$, 20 min) (Thermo Scientific). O tampão de corrida utilizado foi Bolt ${ }^{\mathrm{TM}}$ MES SDS (Life Technologies). $\mathrm{Na}$ sequência, o gel foi fixado e corado com Coomassie Blue G250 0,1\% (Sigma-Aldrich Co., St. Louis, MO) e visualizado em Molecular Imager ${ }^{\circledR}$ Gel Doc ${ }^{\mathrm{TM}}$ XR (Bio-Rad Laboratories Inc., Hercules, CA). O marcador molecular utilizado foi SeeBlue ${ }^{\mathrm{TM}}$ Plus2 Pre-stained Protein Standard (Life Technologies), com marcações de 3 a $198 \mathrm{kDa}$. 


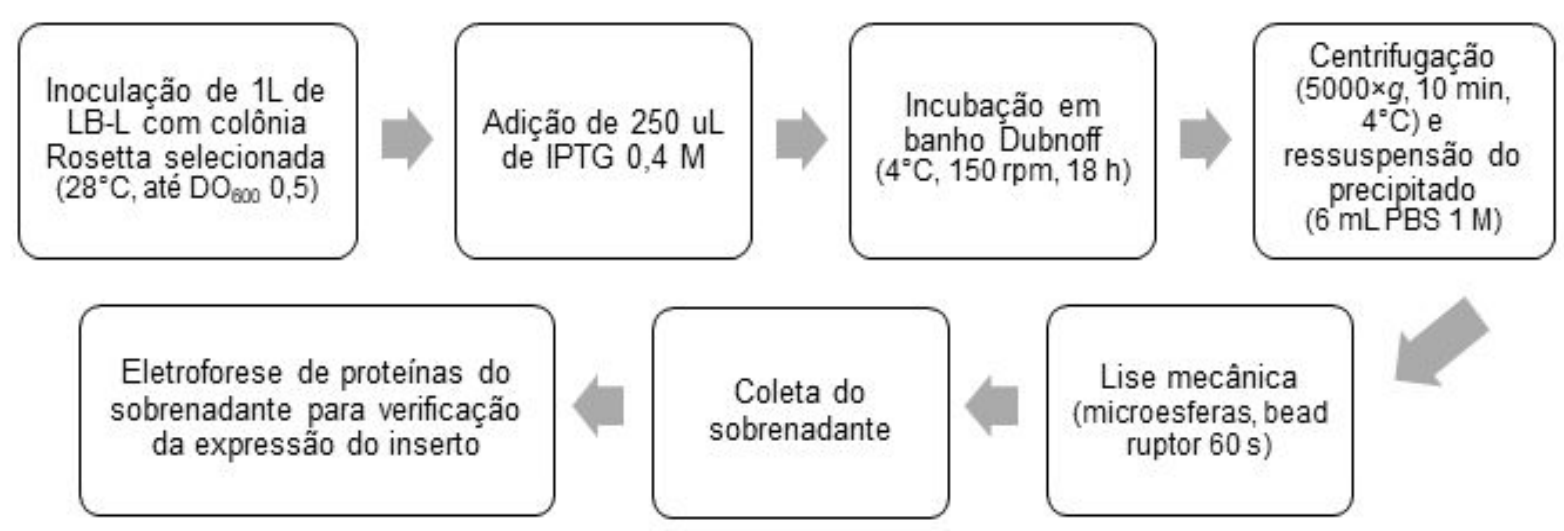

Figura 5. Esquema do procedimento de indução. Após seleção das colônias de E. coli Rosetta transformantes, a indução da expressão proteica foi prosseguida.

\section{Resultados e discussão}

Foi conferida competência às células $E$. coli S17-1, afirmação essa que se baseia em i) presença de crescimento nas placas seletivas (contendo canamicina) após semeadura da cultura resultante do procedimento de transformação utilizando o plasmídeo teste pET-30a(+) extraído de S. melitoti; ii) ausência de crescimento nas placas do controle negativo, que confirmam a não competência e/ou contaminação da cepa original; iii) comparação do DNA plasmidial extraído por kit QIAprep ${ }^{\circledR}$ Spin Miniprep das culturas de S17-1 transformadas e de S. melitoti, mostrando correspondência entre as bandas obtidas.

A propagação do plasmídeo pET-30a(+) foi realizada em E. coli S17-1 competente. A seleção das colônias transformantes e a verificação por eletroforese confirmaram a aquisição dos plasmídeos nas células, de maneira análoga ao explicitado anteriormente na verificação da atribuição de competência. O DNA plasmidial foi extraído e armazenado a $-20{ }^{\circ} \mathrm{C}$. Os plasmídeos teste e pET-30a $(+)$ foram então transformados nas células Rosetta.

A partir da comparação das imagens dos géis proteicos obtidos por eletroforese em gel vertical dos lisados das células Rosetta transformadas pelos plasmídeos pET-30a $(+$ ) (Figura 6b, c) e teste (Figura 6e, f), pode-se observar a presença de uma banda de alta massa molecular (comparada aos marcadores, Figura 6a, d) exclusivamente nas culturas de Rosetta transformadas com pET-30a $(+)$. Isso condiz com o fato da sequência inserida nas células utilizando o vetor codificar, um multímero de aproximadamente $33 \mathrm{kDa}$. Além disso, a adição de IPTG intensifica a cor da banda, embora a expressão já seja bem evidente na cultura não induzida. 


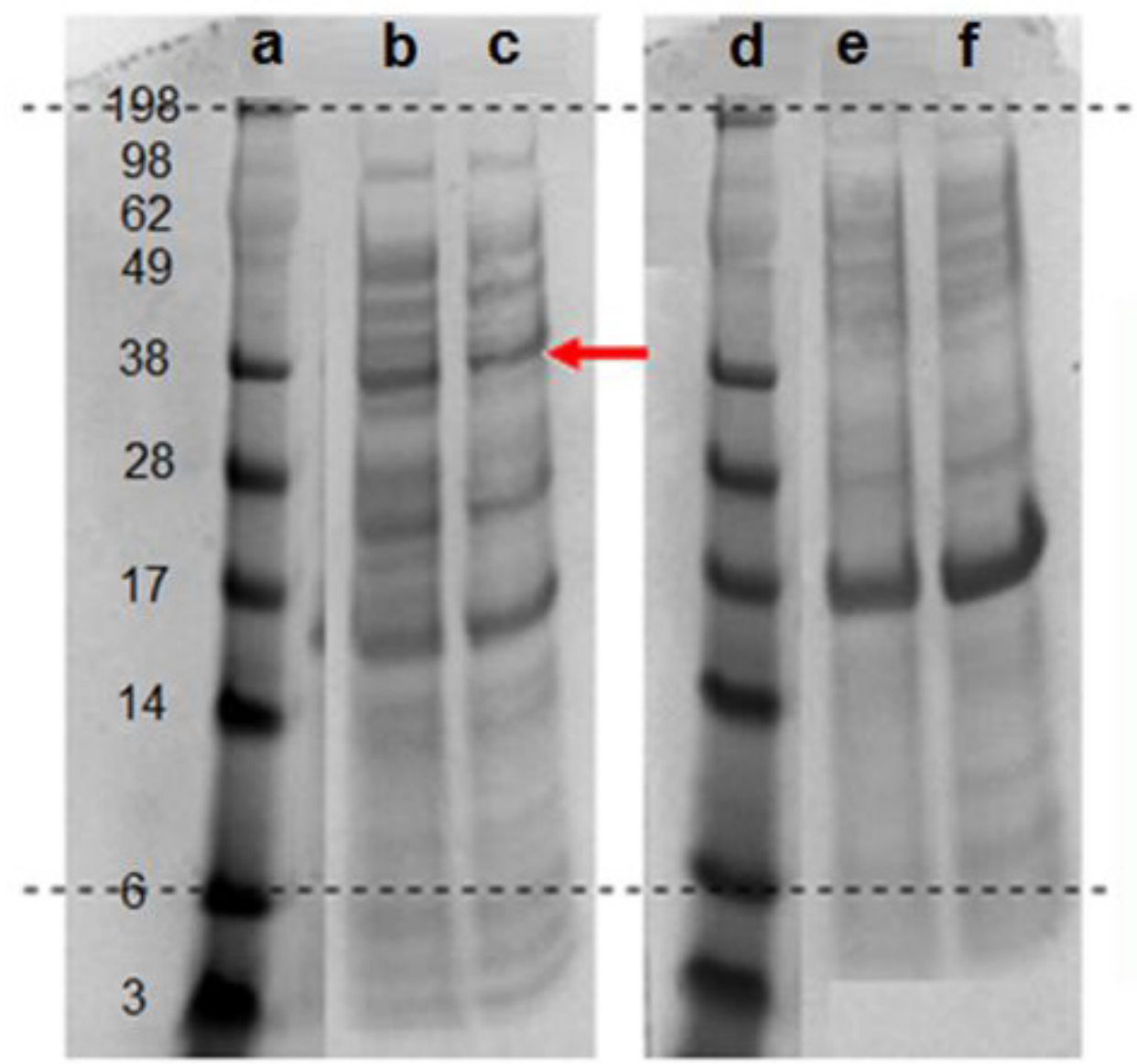

Figura 6. Matrizes de gel obtidas por eletroforese vertical de proteínas. a,d: Marcadores moleculares. Os números ao lado de a indicam a massa em kDa correspondente. b,c: Extratos do cultivo de Rosetta transformadas com o plasmídeo pET-30a(+), sendo b induzido com IPTG e c não induzido. e,f: Extratos do cultivo de Rosetta transformadas com o plasmídeo teste, sendo e induzido com IPTG e f não induzido. A seta indica a posição do multímero peptídico em tandem.

O estabelecimento do sistema de expressão para o plasmídeo pET-30a $(+)$ contendo o inserto Soy_IPS_12 em células Rosetta foi comprovado. Estas células são indicadas pelo fabricante para expressão de proteínas eucarióticas e/ou que possuem potencial de toxicidade à célula hospedeira (Novagen, 2004), ambas características do multímero que será expresso - sequência original proveniente da RuBisCO de soja e com atividade antimicrobiana prevista in silico. A cepa Rosetta vem sendo utilizada nos últimos anos no estabelecimento de sistemas de expressão de genes codificantes de proteínas de organismos eucarióticos, apresentando rendimento elevado (Yedahalli et al., 2016; Toufiq et al., 2018).

Em relação ao multímero expresso com o sistema aqui estabelecido, a configuração do inserto Soy_IPS_12 baseou-se nas etapas de processamento posteriores à sua expressão. Primeiramente, tendo em vista que os multímeros deverão ser isolados do restante do cultivo, a presença da His-tag contida no final do multímero desempenha importante papel. Por ela apresentar afinidade por sais de níquel, a purificação dos multímeros expressos pelas células poderá ser realizada por cromatografia de afinidade por metal imobilizado (IMAC - Immobilized Metal-Affinity Chromatography) (Bewley et al., 2017). Além disso, as 12 repetições em tandem - que auxiliam no maior rendimento da produção do peptídeo GSIKAFKEATKVDKVVVLWTALVPR de RuBisCO, sem prejudicar a incorporação do plasmídeo às células - possuem entre si sítios de clivagem específicos para enzimas proteolíticas, visando à liberação dos peptídeos do multímero. Acredita-se que a trombina, proteinase sérica de baixo custo, possa ser usada nesse processamento, por possuir a característica de clivar entre os aminoácidos arginina (R) e glicina (G) adjacentes (Magnusson, 1968), configuração que o multímero apresenta entre as repetições. Após 
liberação dos peptídeos, as enzimas poderão ser recuperadas para reutilização e os peptídeos liberados estarão ativos para aplicação na indústria. Ressalta-se que testes antimicrobianos deverão ser conduzidos para averiguar a eficiência destes peptídeos frente a patógenos.

Em relação à aplicabilidade de um sistema bacteriano de expressão de peptídeos derivados de RuBisCO na indústria, é destacável que se trate de um processo sustentável, rápido e relativamente barato, uma vez estabelecido. Kobbi et al. (2015) propuseram um método de recuperação e purificação de RuBisCO a partir de suco verde de alfafa, visando aliar um método de hidrólise química da enzima para liberação de frações peptídicas bioativas e, dessa forma, estabelecer um método de potencial aplicação na indústria. O mesmo grupo também estudou a atividade antibacteriana de frações do hidrolisado de RuBisCO, obtendo resultados bastante promissores contra Bacillus subtilis, Listeria innocua, Micrococcus luteus, Escherichia coli, Staphylococcus aureus, Salmonella enterica e Enterococcus faecalis (Kobbi et al., 2015). A atividade antimicrobiana encontrada foi atribuída à alta concentração de peptídeos bioativos nas frações do hidrolisado, corroborando com o potencial dessa enzima em gerá-los, ressaltada no trabalho de Udenigwe et al. (2017).

Outro estudo com hidrolisados proteicos foi conduzido por Beaulieu et al. (2015), no qual foi avaliada a atividade antibacteriana do hidrolisado proteico da macroalga Saccharina longicruris. Os peptídeos responsáveis por essa atividade são originários de diferentes proteínas da alga, com destaque para RuBisCO.

Comparando os métodos de obtenção de peptídeos de RuBisCO, a produção em biorreatores em sistema bacteriano apresenta vantagens em relação aos métodos de purificação da enzima de fontes vegetais e posterior hidrólise. O baixíssimo rendimento, o elevado custo e a extensão desses métodos inviabilizam a utilização em larga escala, essencial à indústria (Udenigwe \& Aluko, 2012; Kobbi et al., 2017). Já a produção a partir do sistema de expressão permite a obtenção de frações peptídicas específicas, sabidamente bioativas, e de configuração determinada visando à facilidade da purificação, demandando menor tempo de processamento com custo reduzido. Além disso, esse sistema pode também ser aplicado em outros ramos da indústria, tal como a nutracêutica, considerando os resultados promissores dos peptídeos e lisados da enzima RuBisCO aplicados na saúde humana e animal (Mohan etal., 2015; Agirbasli \& Cavas, 2017; Udenigwe et al., 2017; Corrêa et al., 2018).

\section{Conclusão}

A partir da indução do sistema de expressão heterólogo estabelecido, será possível a produção do peptídeo codificado pela sequência inserida. Além disso, as metodologias aqui aplicadas poderão ser utilizadas visando à expressão de outras sequências peptídicas. Como neste sistema, os peptídeos poderão ser obtidos em tandem - ou seja, em sequência - intercalados com sítios de clivagem específicos para proteases, já que o inserto os codifica assim -, além da His-tag no final da cadeia. Essas características são essenciais para as etapas de purificação e ativação, etapas que se baseiam na possibilidade de coletar a cadeia dos peptídeos em tandem a partir de IMAC (pela afinidade à His-tag), e na conseguinte digestão proteolítica por trombina, que cliva os sítios específicos presentes entre os peptídeos, liberando-os da cadeia e, assim, conferindo a característica anfipática aos mesmos. Estudos futuros deverão ser conduzidos visando à verificação de tais etapas e à atividade antimicrobiana in vitro da molécula.

\section{Agradecimentos}

Este estudo foi desenvolvido com apoio financeiro da Pró-Reitoria de Pesquisa e Pós-Gradução da Pontifícia Universidade Católica do Paraná, por meio do Programa de Iniciação Científica PIBIC Master Combined Degree (edital 04/2016). 


\section{Referências}

Abdollahzadeh, E., Rezaei, M., \& Hosseini, H. (2014). Antibacterial activity of plant essential oils and extracts: the role of thyme essential oil, nisin, and their combination to control Listeria monocytogenes inoculated in minced fish meat. Food Control, 35(1), 177-183. http://dx.doi.org/10.1016/j.foodcont.2013.07.004

Agirbasli, Z., \& Cavas, L. (2017). In silico evaluation of bioactive peptides from the green algae Caulerpa. Journal of Applied Phycology, 29(3), 1635-1646. http://dx.doi.org/10.1007/s10811-016-1045-7

Beaulieu, L., Bondu, S., Doiron, K., Rioux, L. E., \& Turgeon, S. L. (2015). Characterization of antibacterial activity from protein hydrolysates of the macroalga Saccharina longicruris and identification of peptides implied in bioactivity. Journal of Functional Foods, 17, 685-697. http://dx.doi.org/10.1016/j.jff.2015.06.026

Bewley, M. C., Reinhart, L., Stake, M. S., Nadaraia-Hoke, S., Parent, L. J., \& Flanagan, J. M. (2017). A non-cleavable hexahistidine affinity tag at the carboxyl-terminus of the HIV-1 Pr55Gag polyprotein alters nucleic acid binding properties. Protein Expression and Purification, 130, 137-145. PMid:27721079. http://dx.doi.org/10.1016/j.pep.2016.10.001

Calo, J. R., Crandall, P. G., O'bryan, C. A., \& Ricke, S. C. (2015). Essential oils as antimicrobials in food systems - a review. Food Control, 54, 111-119. http://dx.doi.org/10.1016/j.foodcont.2014.12.040

Corrêa, J. A. F., Udenigwe, C., \& Luciano, F. B. (2018). Avaliação in vitro de atividade antimicrobiana de peptídeos anfipáticos derivados de proteínas do soro de leite. Revista Acadêmica: Ciência Animal, 16, 1-6. http://dx.doi.org/10.7213/19814178.2018.16013

Gasteiger, E., Gattiker, A., Hoogland, C., Ivanyi, I., Appel, R. D., \& Bairoch, A. (2003). ExPASy: the proteomics server for indepth protein knowledge and analysis. Nucleic Acids Research, 31(13), 3784-3788. PMid:12824418. http://dx.doi.org/10.1093/nar/gkg563

GenScript. (2018). Express cloning vectors. Piscataway: GenScript Inc. Recuperado em 07 de agosto de 2018, de https://www.genscript.com/express-cloning-vector-list.html

Hyldgaard, M., Mygind, T., \& Meyer, R. L. (2012). Essential oils in food preservation: mode of action, synergies, and interactions with food matrix components. Frontiers in Microbiology, 3, 12. PMid:22291693. http://dx.doi.org/10.3389/fmicb.2012.00012

Johnson, E. M., Jung, D. Y., Jin, D. Y., Jayabalan, D. R., Yang, D. S. H., \& Suh, J. W. (2018). Bacteriocins as food preservatives: challenges and emerging horizons. Critical reviews in food science and nutrition, 58(16), 2743-2767. PMid:28880573.

Kobbi, S., Balti, R., Bougatef, A., Le Flem, G., Firdaous, L., Bigan, M., Chataigné, G., Chaabouni, S., Dhulster, P., \& Nedjar, N (2015). Antibacterial activity of novel peptides isolated from protein hydrolysates of RuBisCO purified from green juice alfalfa. Journal of Functional Foods, 18, 703-713. http://dx.doi.org/10.1016/j.jff.2015.09.007

Kobbi, S., Bougatef, A., Le Flem, G., Balti, R., Mickael, C., Fertin, B., Chaabouni, S., Dhulster, P., \& Nedjar, N. (2017). Purification and recovery of RuBisCO protein from alfalfa green juice: antioxidative properties of generated protein hydrolysate. Waste and Biomass Valorization, 8(2), 493-504. http://dx.doi.org/10.1007/s12649-016-9589-y

Krantz Laboratory. (2016). Making calcium competent cells. Berkeley: Department Of Molecular \& Cell Biology, University of California. Recuperado em 13 de agosto de 2016, de http://mcb.berkeley.edu/labs/krantz/protocols/calcium_comp_cells.pdf

Kristensen, C. S., Eberl, L., Sanchez-Romero, J. M., Givskov, M., Molin, S., \& Lorenzo, V. (1995). Site-specific deletions of chromosomally located DNA segments with the multimer resolution system of broad-host-range plasmid RP4. Journal of Bacteriology, 177(1), 52-58. PMid:7798149. http://dx.doi.org/10.1128/jb.177.1.52-58.1995

Lopes, L. F., Bordin, K., Lara, G. H., Saladino, F., Quiles, J. M., Meca, G., \& Luciano, F. B. (2018). Fumigation of Brazil nuts with allyl isothiocyanate to inhibit the growth of Aspergillus parasiticus and aflatoxin production. Journal of the science of food and agriculture, 98(2), 792-798. PMid:28675475. https://doi.org/10.1002/jsfa.8527

Luepke, K. H., Suda, K. J., Boucher, H., Russo, R. L., Bonney, M. W., Hunt, T. D., \& Mohr Third, J. F. (2017). Past, present, and future of antibacterial economics: increasing bacterial resistance, limited antibiotic pipeline, and societal implications. Pharmacotherapy, 37(1), 71-84. PMid:27859453. http://dx.doi.org/10.1002/phar.1868

Magnusson, S. (1968). Homologies between thrombin and other serine proteinases. The Biochemical Journal, 110(3), 25-26. PMid:5701647. http://dx.doi.org/10.1042/bj1100025Pb

Meira, N. V. B., Holley, R. A., Bordin, K., Macedo, R. E. F., \& Luciano, F. B. (2017). Combination of essential oil compounds and phenolic acids against Escherichia coli $\mathrm{O} 157: \mathrm{H} 7$ in vitro and in dry-fermented sausage production. International Journal of Food Microbiology, 260(July), 59-64. PMid:28843125. http://dx.doi.org/10.1016/j.ijfoodmicro.2017.08.010

Minkiewicz, P., Dziuba, J., Iwaniak, A., Dziuba, M., \& Darewicz, M. (2008). BIOPEP database and other programs for processing bioactive peptide sequences. Journal of AOAC International, 91(4), 965-980. PMid:18727559.

Mohan, A., Rajendran, S. R. C. K., He, Q. S., Bazinet, L., \& Udenigwe, C. C. (2015). Encapsulation of food protein hydrolysates and peptides: a review. RSC Advances, 5(97), 79270-79278. http://dx.doi.org/10.1039/C5RA13419F

Mooney, C., Haslam, N. J., Pollastri, G., \& Shields, D. C. (2012). Towards the improved discovery and design of functional peptides: common features of diverse classes permit generalized prediction of bioactivity. PLoS One, 7(10), e45012. PMid:23056189. http://dx.doi.org/10.1371/journal.pone.0045012

Nazareth, T. M., Corrêa, J. A. F., Pinto, A. C. S. M., Palma, J. B., Meca, G., Bordin, K., \& Luciano, F. B. (2018). Evaluation of gaseous allyl isothiocyanate against the growth of mycotoxigenic fungi and mycotoxin production in corn stored for 6 months. Journal of the Science of Food and Agriculture, 98(14), 5235-5241. PMid:29652439. http://dx.doi.org/10.1002/jsfa.9061 
Nielsen Europe. (2015). Green generation: millennials say sustainability is a shopping priority. The Nielsen Company. Recuperado em 17 de março de 2017, de http://www.nielsen.com/eu/en/insights/news/2015/green-generation-millennials-saysustainability-is-a-shopping-priority.html

Novagen. (2004). User Protocol TB009 Rev. F 0104 - Competent cells. EMD Biosciences Inc. Recuperado em 17 de março de 2017, de http://post.queensu.ca/ chinsang/lab-protocols/handbooks-and-manuals/novagencompetentcells.pdf

Oren, Z., \& Shai, Y. (1998). Mode of action of linear amphipathic a-helical antimicrobial peptides. Peptide Science, 47(6), 451463. PMid:10333737. http://dx.doi.org/10.1002/(SICI)1097-0282(1998)47:6<451::AID-BIP4>3.0.CO;2-F

Pellegrini, A. (2003). Antimicrobial peptides from food proteins. Current Pharmaceutical Design, 9(16), 1225-1238. PMid:12769733. http://dx.doi.org/10.2174/1381612033454865

Rigotti, R. T., Corrêa, J. A. F., Maia, N. J. L., Cesaro, G., Rosa, E. A. R., Macedo, R. E. F., \& Luciano, F. B. (2017). Combination of natural antimicrobials and sodium dodecyl sulfate for disruption of biofilms formed by contaminant bacteria isolated from sugarcane mills. Innovative Food Science \& Emerging Technologies, 41, 26-33. http://dx.doi.org/10.1016/j.ifset.2017.01.007

Toufiq, N., Tabassum, B., Bhatti, M. U., Khan, A., Tariq, M., Shahid, N., Nasir, I. A., \& Husnain, T. (2018). Improved antifungal activity of barley derived chitinase I gene that overexpress a $32 \mathrm{kDa}$ recombinant chitinase in Escherichia coli host. Brazilian journal of microbiology : [publication of the Brazilian Society for Microbiology], 49(2), 414-421. PMid:29146152.

Udenigwe, C. C. (2014). Bioinformatics approaches, prospects and challenges of food bioactive peptide research. Trends in Food Science \& Technology, 36(2), 137-143. http://dx.doi.org/10.1016/j.tifs.2014.02.004

Udenigwe, C. C., \& Aluko, R. E. (2012). Food protein-derived bioactive peptides: production, processing, and potential health benefits. Journal of Food Science, 77(1), R11-R24. PMid:22260122. http://dx.doi.org/10.1111/j.1750-3841.2011.02455.x

Udenigwe, C. C., Gong, M., \& Wu, S. (2013). In silico analysis of the large and small subunits of cereal RuBisCO as precursors of cryptic bioactive peptides. Process Biochemistry, 48(11), 1794-1799. http://dx.doi.org/10.1016/j.procbio.2013.08.013

Udenigwe, C. C., Okolie, C. L., Qian, H., Ohanenye, I. C., Agyei, D., \& Aluko, R. E. (2017). Ribulose-1,5-bisphosphate carboxylase as a sustainable and promising plant source of bioactive peptides for food applications. Trends in Food Science \& Technology, 69, 74-82. http://dx.doi.org/10.1016/j.tifs.2017.09.001

Yedahalli, S. S., Rehmann, L., \& Bassi, A. (2016). Expression of exo-inulinase gene from Aspergillus niger 12 in E. coli strain Rosetta-gami B (DE3) and its characterization. Biotechnology Progress, 32(3), 629-637. PMid:26833959. http://dx.doi.org/10.1002/btpr.2238

Financiamento: Pró-Reitoria de Pesquisa e Pós-Gradução da Pontifícia Universidade Católica do Paraná, através do Programa de Iniciação Científica PIBIC Master - Combined Degree (edital

04/2016). 